\title{
Estacas de amoreira tratadas com hormônios vegetais em dois sistemas de plantio e referentes coberturas do estufim
}

ANTONIO CASTILHO RUBIA, ROMEU INFORZATO e F. PIMENTEL GOMES

Escola Superior de Agricultura «luiz de Queiroz» 


\section{INTRODUÇÃO}

A amoreira (Morus alba L.) é cultivada no Estado de São Paulo com a finalidade de produção de fôlhas destinadas à alimentação do bicho da sêde. Todavia, o seu rendimento por unidade de área é pequeno, devido à quase totalidade das amoreiras ser constituida de variedades pouco produtivas de fôlhas, como aquelas do grupo das amoreiras Comuns ou Nacionais. Entretanto, estas são mais plantadas pelos sericicultores, por serem propagadas por estaquia, enquanto que as outras variedades, mais produtivas, como a Catania 1, Catania 2, Nezumigaesi e Morettiana, para se propagarem, necessitam enxertia. No entanto, INFORZATO (2) empregou hormônios vegetais nas estacas de amoreira da variedade Catania 1 , obtendo resultados animadores no aumento da percentagem de estacas enraízadas:

No presente trabalho são apresentados os resultados de dois modos de plantio de estacas de amoreira, da variedade Catania 1 , tratadas com diferentes hormônios vegetais, em diferentes tipos de cobertura do estufim.

\section{MATERIAL E MÉTODO}

As estacas de amoreira foram retiradas de ramos da variedade Catania 1 , no dia $25 / 9 / 1962$, com o tamanho médio de 25 centímetros. $O$ corte inferior $d a$ base foi feito cêrca de 1 centimetro abaixo de uma gema. O número de estacas empregado para os diferentes ensaios foi de 960 , divididas em quatro lotes de 240 para cada tipo de ensaio das diferentes coberturas do estufim. Esses lotes por sua vez foram subdivididos em grupos de 120 , destinados a cada um dos diferentes sistemas de plantio. Os hormônios vegetais empregađos para os diferentes tratamentos foram quatro, sendo dois produtos comerciais, na forma de pós insolúveis em água, Dieradix " $M D$ " e o Dieradix " $D$ ", e outros dois na forma de ácidos puros solúveis em álcool, representados pelo ácido beta indel-acético (Indol 3-yl-acetic acid) e pelo ácido alfa naftaleno acético (I-naphthyl acetic acid) . O preparo das soluções dos ácidos puros se processou da seguinte maneira: numa balança de precisão pesaram-se 100 miligramas de cada ácido e depois foram colocados em pequenos frascos de laboratório, onde se adicionaram aos poucos $3 \mathrm{~cm}^{3}$ de ălcool. Em seguida agitou-se com um bastonete de vidro durante alguns minutos, até a sua completa dissolução. Os concentrados foram depois transferidos para 
frascos de Erlenmeyer onde foi colocada água distilada até completar o volume de $1.000 \mathrm{~cm}^{3}$.

As estacas, depois de cortadas, foram reunidas em molhos de 20 unidades. A seguir, os molhos foram colocados em vasilhames de matéria plástica, onde receberam as soluções dos hormônios até a altura de 3 centímetros de suas bases. Feito isto, os vasilhames, juntamente com os molhos de estacas foram colocados num local fora do alcance da luz (1). Para isto, foram protegidos com um pano prêto. Para as estacas testemunhas, colocou-se nos vasilhames sòmente água distilada.

Decorridas 24 horas de permanência das estacas nas soluções e água distilada, foram depois retiradas e as que permaneceram nas soluções, tiveram suas bases lavadas ligeiramente em água corrente antes do seu plantio.

$\mathrm{O}$ ambiente para o enraízamento das estacas constituiu-se de um estufim rústico, dividido em quatro compartimentos iguais. O seu substrato constou de uma camada de 40 centímetros de areia grossa, assentada sôbre outra de cascalho com 10 centímetros de altura.

$\mathrm{Na}$ véspera da instalação dos ensaios o substrato foi abundantemente regado. As estacas foram plantadas no dia 27-9-62, obedecendo a dois tipos de plantio: normal e invertido.

Plantio normal - As estacas tratadas nas soluções dos hormônios, bem como as suas testemunhas, foram introduzidas na areia até a profundidade de $2 / 3$ de seu comprimento e no espaçamento de 5 centimetros uma da outra. No caso dos tratamentos com hormônios em pó, recorreu-se a outra técnica, para evitar a perda dos mesmos. No substrato prèviamente molhado, foram feitos orifícios, com o auxílio de um chuço de madeira de diâmetro maior do que o das estacas, a fim de conter $2 / 3$ de comprimento das mesmas. Antes, porém, de se proceder ao plantio das estacas, as suas bases foram umedecidas em água e em seguida colocadas no hormônio em pó até cêrca de 0,5 centímetros de altura. Depois foram introduzidas nos orifícios, com o cuidado de não atritá-las nas paredes, para não haver perda de pó. Depóis do plantio de cada estaca, a areia foi ligeiramente comprimida a seu redor.

Plantio invertido - Neste sistema de plantio, tanto para as estacas tratadas nas soluções dos hormônios como para as tratadas nos hormônios em pó, foram feitos na areia, com a chuço de madeira, orifícios de 27 centímetros de profundidade. As estacas foram introduzidas nesses orifícios com suas gemas voltadas para baixo. Suas bases, depois de plantadas, permaneceram cêrca de 


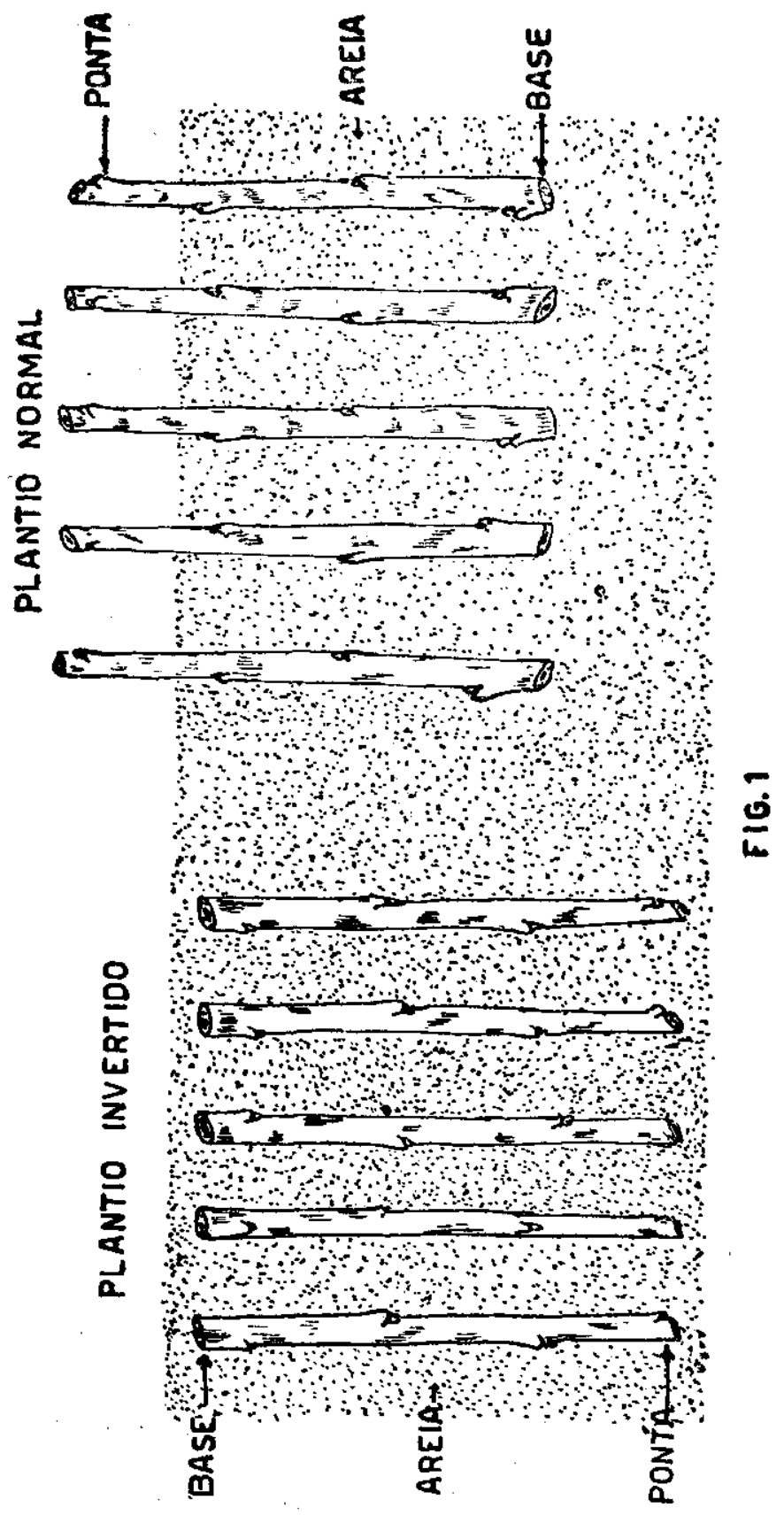


2 centímetros abaixo da superfície da areia do estufim. Em seguida foi colocada mais uma camada de areia para ficarem totalmente encobertas.

Após a instalação, ficaram os ensaios constituídos de duas partes distintas, uma, de "plantio normal", com o têrço das estacas para fora, e outra, de "plantio invertido", com as estacas totalmente introduzidas na areia, como mostra a figura 1.

Concluido o plantio dos ensaios, foi colocada em cada um, a sua cobertura, constituida da seguinte maneira:

Ensaio A - Cobertura de vidros opacos.

Ensaio B - Cobertura de matéria plástica.

Ensaio $\mathrm{C}$ - Cobertura de aniagem branca recoberta com tinta a óleo, até o $300^{\circ}$ dia, e depois substituída pelo tipo de cobertura do Ensaio B.

Ensaio D - Mesmo tipo de cobertura do Ensaio C, até o $300^{\circ}$ dia de idade, retirada posteriormente, ficando o ensaio ao ar livre, apenas protegido pelo ripado de bambu sôbre o estufim.

Nos primeiros cinco dias após o plantio, as regras foram leves, apenas para repôr a água evaporada da superfície da areia, bem como para evitar também por lavagem a perda do hormônio em pó aderido nas bases das estacas. Do $60^{\circ}$ dia em diante, porém, foram feitas regas abundantes devido à areia já apresentar indício de ressecamento nas partes mais profundas.

\section{COMPORTAMENTO DOS ENSAIOS E RETIRADA DAS ESTACAS}

Depois do $100^{\circ}$ dia do plantio, as estacas do "plantio normal" entraram em brotação, bastante desuniforme, porém, sendo que nos ensaios C e D os brotos apresentaram-se estiolados, devido aos seus tipos de cobertura. Dez dias mais tarde, no "plantio invertido" apareceram fora da areia, na parte superior, numerosas raizes formadas nas bases das estacas. Para evitar o seu ressecamento ao àr, colocou-se sôbre elas uma camada fina de areia umedecida.

No dia $2 / 10 / 62$, a cobertura do ensaio $C$ foi substituida por outra semelhante à do ensaio $\mathrm{B}$; e a cobertura do ensaio $\mathrm{D}$ foi retirada, ficando o mesmo apenas protegido pelo ripado do estufim.

Tendo em todos os ensaios do "plantio invertido" aumentado bastante a quantidade de raizes na parte superior da areia prove- 
niente das bases das estacas invertidas, procedeu-se, no dia 10/11/62, a sua retirada, da seguinte maneira: com uma colher própria abriu-se um sulco paralelo à primeira fileira de estacas, distante 5 centímetros e com 20 centímetros de profundidade, tomando-se o cuidado de evitar o rompimento das raízes. As raízes do "plantio invertido", além de se apresentarem bastante desenvolvidas, eram abundantes e vigorosas.

No dia 20/11/62, foram retiradas as estacas do "plantio normal", observando-se a mesma técnica anterior. As estacas enraizadas, obtidas nesse caso, apresentaram suas raizes mais curtas, menos abundantes e mais frágeis do que as do "plantio invertido". As estacas do ensaio A, talvez devido ao excesso de calor e umidade, proporcionados pela sua cobertura, apresentaram suas cascas bastante tomadas de um bolor esbranquiçado.

Conforme se verifica pelo Quadro I, os melhores resultados apresentados em percentagem de estacas enraizadas foram obtidos pelo processo do "plantio invertido".

\section{ANÁLISES ESTATISTICAS E DISCUSSÃO}

Estudamos as percentagens ( $p$ ) de estacas enraízadas, transformadas pela fórmula $y=\operatorname{arc} \operatorname{sen} V p / 100(3)$. Analisamos separadamente cada um dos quatro ensaios, e a seguir fizemos uma análise conjunta dêles, sempre com os dados transformados.

Ensaio A (Cobertura de vidros opacos)

Análise de Variância

\begin{tabular}{lrrrrr}
\hline Causa de variação & G. L. & S. Q. & Q. M. & F \\
\hline Métodos de plantio & 1 & $3.711,1340$ & $3.711,1340$ & $32,25 * *$ \\
Hormônios & 5 & $2.952,6450$ & 590,5290 & $5,13 *$ \\
Resíduo & 5 & 575,2913 & 115,0583 & \\
\hline
\end{tabular}

A análise estatística mostrou-se significativa para os componentes "métodos de plantio" e "hormônios". . As médias de métodos de plantio, que diferem significativamente o nivel de $1 \%$ de probabilidade, são as seguintes: 


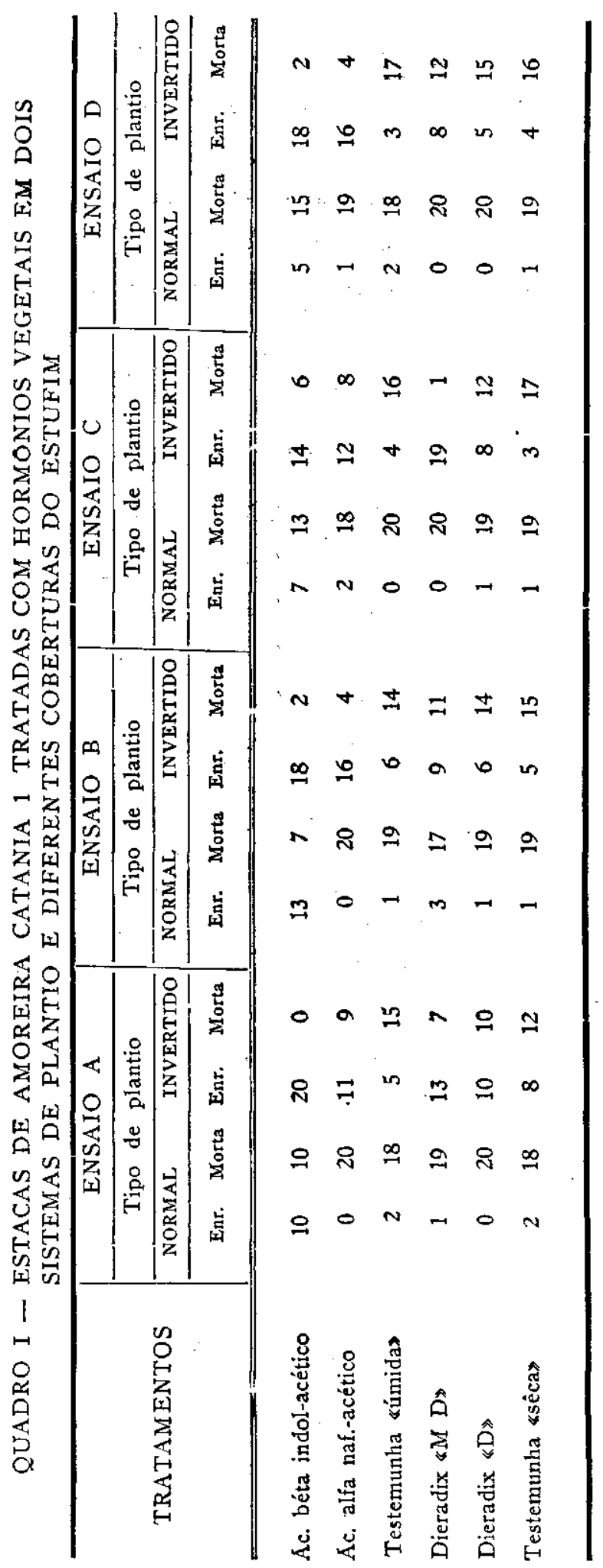


Dados transformados Percentagens

Plantio invertido

$$
50,97 \pm 4,38 \quad 60,4 \%
$$

Plantio normal

$15,80 \pm 4,38$

$7,4 \%$

As médias para hormônios são dadas a seguir:

Dados transformados Percentagens

$\begin{array}{llll}\text { Ac. beta indol-acético } & 67,50 \pm 7,58 & 85,4 \% \\ \text { Dieradix «M D» } & 33,32 \pm 7,58 & 30,2 \% \\ \text { Testemunha «sêca» } & 28,83 \pm 7,58 & 23,3 \% \\ \text { Testemunha «úmida» } & 24,22 \pm 7,58 & 16,8 \% \\ \text { Ac. alfa naft. acético } & 23,93 \pm 7,58 & 16,4 \% \\ \text { Dieradix «D» } & 22,50 \pm 7,58 & 14,6 \%\end{array}$

A diferença mínima significativa, calculada pelo teste de Tukey, ao nivel de $5 \%$ de probabilidade, foi de 45,40. Vemos, pois, que não há diferença significativa entre as duas quaisquer das 6 médias de hormônios; o que deve haver é uma diferença significativa para um contraste envolvendo mais de duas médias. O coeficiente de variação foi de $32,1 \%$.

Ensaio B (Cobertura de matéria plástica) Análise i đe variância

$\begin{array}{lrrrc}\text { Causa da variação } & \text { G. L. } & \text { S. Q } & \text { Q. M. } & \text { F } \\ \text { Métodos de plantio } & 1 & 2.087,4490 & 2.087,4490 & 12,60 * \\ \text { Hormônios } & 5 & 2.418,3880 & 483,6776 & 2,52 \\ \text { Resíduo } & 5 & 828,3875 & 165,6775 & \end{array}$

A análise da variância mostrou efeito significativo sòmente para "métodos de plantio", cujas médias, tôdas com êrro padrão de 5,25 são as seguintes: 
Dados transformados Percentagens

\begin{tabular}{lll}
\hline Plantio invertido & $45,59 \pm 5,25$ & $51,0 \%$ \\
Plantio normal & $19,21 \pm 5,25$ & $10,8 \%$
\end{tabular}

Como vemos, foi o plantio invertido que deu maior percentagem de estacas enraizadas.

Apesar de não serem significativos os efeitos de "hormônios", damos a seguir as suas médias:

Dados transformados Percentagens

\begin{tabular}{lll}
\hline Ac. beta indol-acético & $62,64 \pm 9,10$ & $78,9 \%$ \\
Dieradix «M D» & $32,46 \pm 9,10$ & $28,8 \%$ \\
Ac. alfa naft. acético & $31,72 \pm 9,10$ & $27,6 \%$ \\
Testemunha «úmida» & $23,06 \pm 9,10$ & $15,3 \%$ \\
Dieradix «D» & $23,06 \pm 9,10$ & $15,3 \%$ \\
Testemunha «sêca» & $21,46 \pm 9,10$ & $13,4 \%$ \\
\hline
\end{tabular}

O coeficiente de variação do ensaio foi de $33,9 \%$, o que é um tanto alto.

Ensaio C (Cobertura de aniagem até o 30.0 dia, substituida a seguir por matéria plástica).

Análise de variância

\begin{tabular}{lcrrc}
\hline Causa da variação & G. L. & S. Q. & Q. M. & F \\
\hline Métodos de plantio & 1 & $3.093,4774$ & $3.093,4744$ & $11,39 *$ \\
Hormônios & 5 & $1.616,4528$ & 323,2906 & 1,19 \\
Resíduo & 5 & $1.357,8717$ & 271,5743 & \\
\hline
\end{tabular}

Aqui também foi só significativo o efeito de "métodos de plantio", cujas médias são: 


\section{Dados transformados Percentagens}

$\begin{array}{llr}\text { Plantio invertido } & 45,54 \pm 6,73 & 50,9 \% \\ \text { Plantio normal } & 13,42 \pm 6,73 & 5,4 \%\end{array}$

Logo foi o "plantio invertido" que deu maior percentagem de estacas enraizadas.

As médias dos hormônios, são:

Dados transformados Percentagens

\begin{tabular}{lll}
\hline Ac. beta indol-acético & $46,53 \pm 11,65$ & $52,7 \%$ \\
Dieradix «M D» & $38,54 \pm 11,65$ & $38,8 \%$ \\
Ac. alfa naft. acético & $34,60 \pm 11,65$ & $32,2 \%$ \\
Dieradix \&D» & $26,07 \pm 11,65$ & $19,3 \%$ \\
Testemunha «sêca» & $17,85 \pm 11,65$ & $9,4 \%$ \\
Testemunha «úmida» & $13,28 \pm 11,65$ & $5,3 \%$ \\
\hline
\end{tabular}

bastante alto.

Ensaio $D$ ( $O$ mesmo tipo de cobertura do ensaio $C$ até o 30.0 dia, depois retirada ficando as estacas apenas protegidas pelo ripado do estufim).

Análise de variância

\begin{tabular}{lcrrc}
\hline Causa da variação & G. L. & S. Q. & Q. M. & F \\
Métodos de plantio & 1 & $2.679,0409$ & $2.679,0409$ & $17,11 * *$ \\
Hormônios & 5 & $1.963,7481$ & 392,7496 & 2,51 \\
Residuos & 5 & 782,6936 & 156,5387 & \\
\hline
\end{tabular}

A análise da variância indicou como significativos só os efeitos de "métodos de plantio", cujas médias são as seguintes: 
Dados transformados Percentagens

\begin{tabular}{lrr}
\hline Plantio invertido & $42,26 \pm 5,11$ & $45,2 \%$ \\
Plantio normal & $12,38 \pm 5,11$ & $4,6 \%$ \\
\hline
\end{tabular}

As médias dos hormônios são:

Dados transformados Percentagens

\begin{tabular}{lll}
\hline Ac. beta indol-acético & $50,78 \pm 8,91$ & $60,0 \%$ \\
Ác. alfa naft. acético & $38,18 \pm 8,91$ & $38,2 \%$ \\
Testemunha «úmida» & $20,61 \pm 8,91$ & $12,4 \%$ \\
Testemunha «sêca». & $19,74 \pm 8,91$ & $11,4 \%$ \\
Dieradix «M D» & $19,61 \pm 8,91$ & $11,3 \%$ \\
Dieradix «D» & $15,00 \pm 8,91$ & $6,7 \%$
\end{tabular}

$O$ coeficiente de variação do ensaio foi de $45,8 \%$.

Em resumo, em todos os ensaios houve reação significativa para "métodos de plantio", sendo o plantio invertido o que deu maior porcentagem de estacas enraízadas. Os efeitos dos "hormônios" se mostraram significativos sòmente no ensaio $\mathrm{A}$.

\section{Análise conjunta dos quatro ensaios}

Cómo os quadrados médios residuais dos quatro ensaios não diferem entre si, sendo o maior 271,5743 e o menor dêles 115,0583 , podemos fazer a análise conjunta sem maiores embaraços, usando sempre dados transformados pela fórmula $y=\operatorname{arc} \operatorname{sen} \sqrt{\mathrm{p} / \overline{100}}$. Os resultados obtidos são dados a seguir .- 
Análise de variância

\begin{tabular}{lcrrr}
\hline Causa da variação & G. L. & S. Q. & Q. M. & \multicolumn{1}{c}{ F } \\
Métodos de plantio (P) & 1 & $11.447,5253$ & $11.447,5253$ & 105,65 ** \\
$\begin{array}{l}\text { Tratamento do estufim } \\
\text { (T. E.) }\end{array}$ & 3 & 276,0093 & 92,0031 & 0,85 \\
Hormônios (H) & 5 & $7.621,9970$ & $1.524,3994$ & 14,07 ** \\
Interação P x T. E. & 3 & 123,5808 & 41,1936 & 0,38 \\
Interação P x H & 5 & $1.918,9280$ & 383,7856 & $3,54 *$ \\
Interação T. E. x H & 15 & $1.329,2364$ & 88,6158 & 0,82 \\
Residuo & 16 & $1.625,3083$ & 108,3539 & \\
\hline
\end{tabular}

Ainda na análise conjunta houve efeito significativo de "métodos de plantio", cujas médias são:

Dados transformados Percentagens

\begin{tabular}{lrr}
\hline Plantio invertido & $46,09 \pm 2,12$ & $51,9 \%$ \\
Plantio normal & $15,20 \pm 2,12$ & $6,9 \%$ \\
\hline
\end{tabular}

Portanto o "plantio invertido" em todos os ensaios foi o que deu maior percentagem de estacas enraizadas.

O fator "hormônios" também se mostrou significativo. As suas médias são:

\section{Dados transformados Percentagens}

\begin{tabular}{lll}
\hline Ac. beta indol-acético & $58,86 \pm 3,68$ & $70,1 \%$ \\
Ac. alfa naft. acético & $32,11 \pm 3,68$ & $28,3 \%$ \\
Dieradix «M D» & $30,98 \pm 3,68$ & $26,5 \%$ \\
Testemunha «sêca» & $21,97 \pm 3,68$ & $14,0 \%$ \\
Dieradix «D» & $21,66 \pm 3,68$ & $13,6 \%$ \\
Testemunha «úmida» & $20,29 \pm 3,68$ & $12,0 \%$ \\
\hline
\end{tabular}


A diferença mínima significativa, calculada pelo teste de Tukey, ao nivel de $5 \%$ de probabilidades, foi de 22,04 . Por esta diferença vemos que a média de hormônio ácido beta indol-acético difere significativamente das médias dos outros hormônios, mas êstes não diferem estatìsticamente entre si.

$\mathrm{Na}$ análise conjunta também a interação métodos de plantio $x$ hormônios mostrou-se significativa, o que indica um comportamento um tanto diferente dos hormônios em relação aos métodos de plantio.

A conclusão lógica a que somos levados é a de que o comportamento de hórmônios está na dependência de método de plantio, pelo menos em parte.

As médias dos hormônios para cada um dos métodos de plantio, são dadas abaixo:

PLANTIO NORMAL

PLANTIO

INVERTIDO

\begin{tabular}{lrrrr} 
& $\begin{array}{c}\text { Dados } \\
\text { transf. }\end{array}$ & Percent. & $\begin{array}{l}\text { Dados } \\
\text { transf. }\end{array}$ & Percent. \\
Ac. beta indol-acét. & 41,25 & $43,5 \%$ & 72,48 & $90,9 \%$ \\
Ac. alfa naft. acét. & 7,84 & $1,9 \%$ & 56,38 & $69,3 \%$ \\
Testemunha «úmida» & 12,45 & $4,7 \%$ & 28,14 & $22,2 \%$ \\
Dieradix «M D» & 8,93 & $2,4 \%$ & 53,04 & $63,8 \%$ \\
Dieradix «D» & 6,46 & $1,3 \%$ & 36,86 & $36,0 \%$ \\
\hline
\end{tabular}
elevado.

$O$ coeficienfe de variação achado foi de $34,0 \%$, bastante

\section{CONCLUSOEES}

5.1 Não há o menor indício de efeito da cobertura do estufim sôbre o pegamento das estacas.

5.2 O plantio invertido é superior ao normal; pois dá percentagens significativamente mais elevadas de enraízamento.

5.3 O ácido beta indol-acético deu resultado significativamente melhor do que a testemunha e do que os demais hormônios utilizados. 


\section{SUMMARY}

Four experiments on root formation on cuttings of mulberry trees of the variety Catania 1 were carried out. In each case the hormones Dieradix " $M \mathrm{D}$ ", Dieradix " $D$ ", indol 3-yl-acetic acid, and I-naphthyl acetic acid were used, besides the control, without hormone. In all cases "normal" and "upside-down" planting were tried. The percentage $x$ of cuttings with roots, after 54 days, were computed and transformed by the formula $y=\arcsin \sqrt{\frac{\mathrm{P}}{100}}$ for use in statistical analysis. The combined analysis of variance of the 4 trials led to the following results:

6.1 "Upside-down" planting showed significantly higher percentage of rooting;

6.2 Indol 3-yl-acetic acid was significantly better than control or other hormones.

The percentages of rooted cuttings were as follows:

Normal planting

$43.5 \%$

$1.9 \%$

$4.7 \%$

$2.4 \%$

$1.3 \%$
Upside-dow planting

Indol 3-yl acetic acid

I-naphthyl acetic acid

Control

Dieradix \&M D»

Dieradix \&D»
$90.9 \%$

$69.3 \%$

$22.2 \%$

$63.8 \%$

$36.0 \%$

\section{LITERATURA CITADA}

1 - GERHARD, NAUNDORF - Las fitohormonas en Agricultura Salvat Editores S. A\}, 1951.

2 - INFORZATO, R. - O emprêgo de hormônios no enraízamento de estacas de amoreira. Bragantia 10: 385/387 - 1950.

4 - PIMENTEL GOMES, F. - Curso de Estatística Experimental (2.a ediçăo), 384 pg. + 15 tabelas. 1963. 